\title{
Application of ultrasound for quality control of Torta del Casar cheese ripening
}

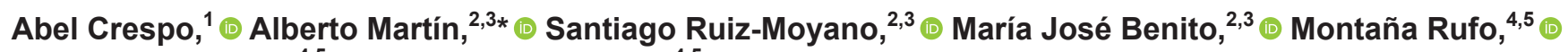 \\ Jesús M. Paniagua, ${ }^{4,5}$ and Antonio Jiménez ${ }^{4,5}$ (D) \\ ${ }^{1}$ National Technological Centre for Food and Agriculture "Extremadura" (CTAEX), Ctra. Villafranco a Balboa km. 1.2, Villafranco del Guadiana, \\ 06195 Badajoz, Spain \\ ${ }^{2}$ Food Science and Nutrition, School of Agricultural Engineering, University of Extremadura, Avda. Adolfo Suárez s/n, 06071 Badajoz, Spain \\ ${ }^{3}$ University Research Institute of Agro-Food Resources (INURA), Avda. de la Investigación s/n, Campus Universitario, 06006 Badajoz, Spain \\ ${ }^{4}$ Department of Applied Physics, School of Technology, University of Extremadura, Avenida de la Universidad s/n, 10003 Cáceres, Spain \\ ${ }^{5}$ Research Institute of Meat and Meat Product, University of Extremadura, Avenida de la Universidad s/n, 10003 Cáceres, Spain
}

\section{ABSTRACT}

This work aimed to establish the ultrasound parameters that can be useful to classify the defects in the soft cheese Torta del Casar during ripening. During ripening by ultrasound, 1 standard and 3 defective cheese batches (anomalous microbial population, inadequate pressing curd, and excessive pressing curd) were evaluated. Ultrasound parameters related to velocity, attenuation, and frequency were calculated and correlated with the physicochemical and rheological properties of the cheeses. Ultrasound data were considered variables in linear discriminant analysis to attempt cheese classification at different periods of the ripening process. Defective soft cheeses could be discriminated from standard ones with good accuracy, mainly at the final stages of ripening. The differentiation of cheese samples from 2 of the defective cheese batches (anomalous microbial population and inadequate pressing curd) from the standard was mainly attributed to different values of the attenuation-related parameters, whereas for samples from the other defective batch (excessive pressing curd), some parameters related to velocity and frequency were responsible for such discrimination.

Key words: Torta del Casar, ultrasound, defect classification, linear discriminant analysis

\section{INTRODUCTION}

Torta del Casar is a high-quality Spanish cheese marketed under the Registry of the Protected Designation of Origin Torta del Casar, in accordance with Regulation (EC) 1491/2003 (European Commission, 2003). This type of soft-bodied cheese is made from raw ewe milk

Received January 5, 2020.

Accepted May 30, 2020.

*Corresponding author: amartin@unex.es using only vegetable coagulant as rennet and without any added starter culture. The absence of a standardizing thermal process means the final characteristics depend on the indigenous microbiota present (Ordiales et al., 2013a,b). In addition, the milk-clotting activity of the traditional vegetable coagulant, prepared using an aqueous infusion of the dried flowers from Cynara cardunculus L., presents great variability. Ordiales et al. (2012) showed that the diverse natural populations harvested at different flower ripening stages, mixed with other parts of the plant and dried in different conditions, strongly influence its coagulant properties. This major heterogeneity in Torta del Casar manufacture can negatively affect the quality parameters, including low product yield, and inhomogeneity of relevant sensorial factors between cheese batches, such as texture parameters (Tunick, 2000). Ordiales et al. (2013b) revealed that the uncontrolled growth of heterofermentative lactic acid bacteria (LAB) adversely influences the flavor of Torta del Casar. Likewise, the clotting and proteolytic activities of vegetable rennets used in the manufacturing of soft-type cheeses affect both the physicochemical parameters in the initial stages and the texture and sensorial properties of the final product (Ordiales et al., 2014). Thus, technological quality control during the cheese-making process by fast, reliable methods would be desirable for standardization of this high-quality product.

Highlighted among the nondestructive techniques for assessing food properties are small-displacement probes; vibration rheometers; visible-, near-, and mid-infrared spectroscopy; z-nose (advanced electronic nose); nuclear magnetic resonance spectroscopy; electronic noses; computer vision; and ultrasound (Benedito et al., 2006). Ultrasound-based technologies have been proposed as a quality control tool not only to determine the optimum cut time during cheese manufacture (Koc and Ozer, 2008; Jiménez et al., 2017) but also to detect 
process anomalies in-line (Telis-Romero et al., 2011). Other researchers used contact or noncontact ultrasound to detect defects and internal objects in cheeses (Lee et al., 1992; Hæggström and Luukkala, 2001; Leemans and Destain, 2009) and to evaluate the texture of cheeses such as Cheddar, Mahon, and Manchego (Benedito et al., 2000, 2002, 2006; Cho et al., 2001; Cho and Irudayaraj, 2003; Nassar et al., 2010). Most studies carried out to detect texture defects in cheese using ultrasound have measured ultrasonic velocity and attenuation at one or more temperatures. In the present work, defective Torta del Casar batches were analyzed by ultrasound during ripening, and several ultrasound parameters related to the velocity, frequency, and attenuation were correlated with the physicochemical and texture parameters of the cheese and used to discriminate these defective batches from standard samples at the ripening temperature.

The objective of this work was to assess the feasibility of ultrasound as a tool for quality control in ripening of Torta del Casar, relating the ultrasonic parameters to the physicochemical and texture characteristics of the cheeses. In addition, ultrasonic parameters were used to discriminate between standard cheeses and defective products throughout the cheese-making process.

\section{MATERIALS AND METHODS}

\section{Torta del Casar Cheese-Making Procedure}

The cheeses were made with a mixture of raw milk obtained from the Merino and Entrefino breeds. The milk was heated in a $100-\mathrm{L}$ stainless-steel vat to 28 to $30^{\circ} \mathrm{C}$ and clotted by adding $10 \mathrm{~mL}$ of the aqueous extract from flowers of the cardoon $C$. cardunculus $\mathrm{L}$. per liter of milk, prepared by macerating $50 \mathrm{~g}$ of dried flowers in $1 \mathrm{~L}$ of water for $24 \mathrm{~h}$. After the curd formed, it was broken at $30^{\circ} \mathrm{C}$ into rice grain-sized pieces using fine metallic threads agitated for $10 \mathrm{~min}$, followed by 10 min of rest and 10 min of stirring. Afterward, it was transferred to suitable molds and pressed for $2 \mathrm{~h}$ at an initial pressure of $2 \mathrm{~kg} / \mathrm{cm}^{2}$, which was increased by 0.5 $\mathrm{kg} / \mathrm{cm}^{2}$ every $30 \mathrm{~min}$. Once pressed, the cheese was submerged in brine $(16 \% \mathrm{NaCl}$, wt/vol) for $4 \mathrm{~h}$. Ripening was controlled at 5 to $7^{\circ} \mathrm{C}$ and relative humidity $>90 \%$ for $70 \mathrm{~d}$. Four batches of Torta del Casar cheese were prepared (Supplemental Figure S1, https://doi.org/10 .3168/jds.2020-18160), introducing a specific modification during the cheese-making procedure, as follows:

- Standard batch (ST): this cheese was manufactured by following the general cheese-making procedure.
- Pressing defect batch 1 (PD1): for the preparation of body mechanical hole defects, cold water was used instead of hot water in the doublejacketed vat during the stirring step. With this cheese-making modification, grains become cold when the curd is shaped, causing ineffective binding among the various curd parts.

- Pressing defect batch 2 (PD2): the curd was broken into rice grain-sized pieces, as indicated in the general cheese-making procedure, but the vat was set at $35^{\circ} \mathrm{C}$ rather than $30^{\circ} \mathrm{C}$ to achieve a higher moisture in the paste.

- Microbial defect batch (MD): the cheese with early blowing defects was prepared by adding 3.61 $\mathrm{g}$ of lyophilized inoculum to $96 \mathrm{~L}$ of milk tempered at $30^{\circ} \mathrm{C}$ before clotting. The inoculum comprised proteolytic and potential gas-producing microorganisms, including Escherichia coli $\left(2.07 \times 10^{10}\right.$ $\mathrm{cfu} / \mathrm{g})$, Enterobacter aerogenes $\left(3.2 \times 10^{10} \mathrm{cfu} / \mathrm{g}\right)$, and Kluyveromyces lactis $\left(1.19 \times 10^{10} \mathrm{cfu} / \mathrm{g}\right)$.

A total of 30 to 32 units were obtained for each batch with approximately $950 \mathrm{~g}$ as initial weight (diameter: $13 \mathrm{~cm}$; height: $7 \mathrm{~cm}$ ). Three cheeses were randomly chosen from each batch for analysis after $0,2,4,6,8$, and $10 \mathrm{wk}$ of ripening.

\section{Physicochemical Parameters}

Dry matter (\%), total protein, and total fat were analyzed using standard methods 5534:2004 (ISO, 2004), 3433:2008 (ISO, 2008), and 8968-1:2014 (ISO, 2014), respectively. Ash content was determined by incineration in a muffle furnace at $550^{\circ} \mathrm{C}$ (AOAC International, 2000). The $\mathrm{pH}$ was determined using a Crison 2002 pH meter (Crison Instruments, Barcelona, Spain). In addition, each cheese was weighed, and the diameter and height were measured using a caliper. Density was calculated, assuming a cylindrical geometry.

\section{Microbial Count}

Ten-gram aliquots of each cheese sample were aseptically transferred to sterile plastic pouches for microbial enumeration. After 10-fold dilution with $1 \%$ peptone water (Pronadisa, Alcobendas, Madrid, Spain), each sample was homogenized for 120 s using a Stomacher Lab Blender 400 (Seward Ltd., London, UK). Serial 10fold dilutions were prepared from the same solution and inoculated onto agar plates. The LAB were grown on de Man, Rogosa and Sharpe agar (Oxoid, Hampshire, UK) acidified to $\mathrm{pH} 5.6$ with acetic acid (10\%) under 
anaerobic conditions at $30^{\circ} \mathrm{C}$ for $48 \mathrm{~h}$. Mold and yeast counts were determined on oxytetracycline-glucoseyeast extract agar (Oxoid) at $25^{\circ} \mathrm{C}$ for $5 \mathrm{~d}$, counting typical colonies. Violet red bile-glucose agar (Oxoid) was used for Enterobacteriaceae counts at $30^{\circ} \mathrm{C}$ for $24 \mathrm{~h}$.

\section{Texture}

A TA.XTplus texture analyzer, fitted with a $5-\mathrm{kg}$ load cell (Stable Micro Systems, Godalming, UK) and spherical stainless-steel probe $(\mathrm{P} / 1 \mathrm{~S})$, was used to perform a texture compression analysis of the cheeses throughout the ripening process. Cheeses were removed from storage at $5^{\circ} \mathrm{C}$, positioned under the probe, and measured on both sides (top and bottom). The operational parameters were as follows: pretest speed, $3 \mathrm{~mm} / \mathrm{s}$; test speed, $2.00 \mathrm{~mm} / \mathrm{s}$; posttest speed, $10.00 \mathrm{~mm} / \mathrm{s}$; distance, $10.0 \mathrm{~mm}$; and trigger force, 25 g. From the resulting graphs, the values for firmness and stickiness of cheese were analyzed using the installed Exponent software version 3.0.5.0 (http://www .stablemicrosystems.com/).

In addition, a texture spreadability analysis was undertaken after approximately 4 wk of ripening, when the Torta del Casar had acquired a creamy appearance, using a TTC Spreadability Rig (HDP/SR) attachment (Texture Technologies Corp., Hamilton, MA) for the spreadability probe. The samples were packed into the lower cone with a spatula and measured at $20^{\circ} \mathrm{C}$. The operational parameters were as follows: pretest speed, $3 \mathrm{~mm} / \mathrm{s}$; test speed, $2.00 \mathrm{~mm} / \mathrm{s}$; posttest speed, 10.00 $\mathrm{mm} / \mathrm{s}$; distance, $10.0 \mathrm{~mm}$; and trigger force, $25 \mathrm{~g}$. From the resulting graphs, the maximum force (the point at which the probe was at its maximum penetration depth) was calculated using the installed Exponent software version 3.0.5.0 and described as unctuosity.

\section{Ultrasonic Parameters}

The cheeses were inspected ultrasonically using contact techniques in through-transmission mode. The measurement setup is illustrated schematically in Figure $1 \mathrm{~A}$. To reduce the operator risk, the transducers were mounted on a custom-designed metal structure that ensured their perfect face-to-face alignment (Figure 2). The range of frequencies used in the study of cheese specimens was extended by using 2 different pairs of shear wave transducers of $250-$ and $500-\mathrm{kHz}$ frequencies, respectively (Olympus Panametrics NDT, Waltham, MA). Table 1 lists the principal characteristics of the different transducers used, including the near-field zone and the beam spread angle. Both of these values depend on the propagation medium, so Table 1 also provides approximate values for cheeses,

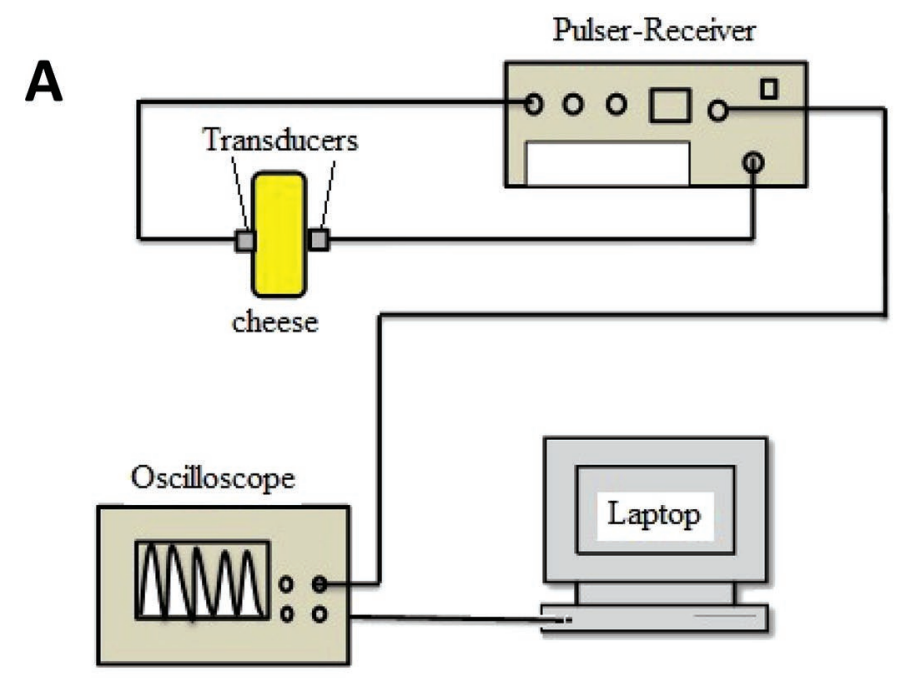

B

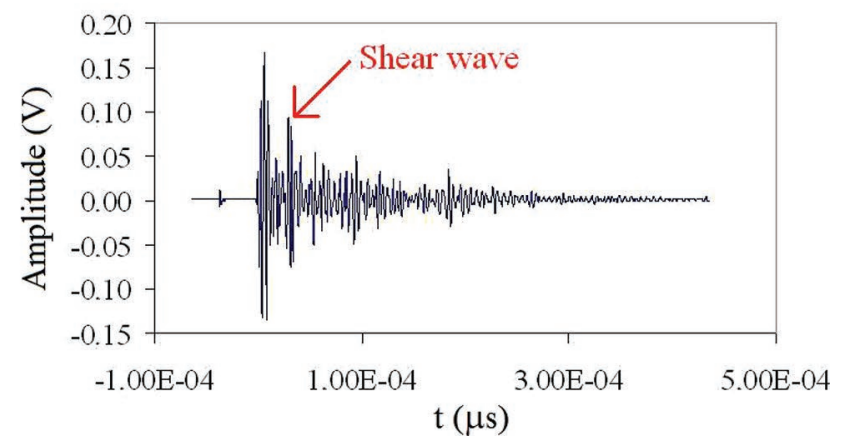

Figure 1. (A) Scheme of the setup used for the ultrasound inspection of the cheeses, and (B) typical A-scan (amplitude vs. time, t) obtained with one of the shear wave transducers.

considering a mean ultrasonic pulse velocity (UPV) of $750 \mathrm{~m} / \mathrm{s}$ for shear waves. The pulser-receiver models 5058PR and 5077PR (Olympus Panametrics NDT) were used for emission and reception of the ultrasonic signals with transducers V150 and V151, respectively. For the acquisition and digitization of the signals, the pulser-receiver units were connected to an oscilloscope (100-MHz bandwidth, 1-GSa/s sample rate, 2.5k points record length; Tektronix TM TDS1012B, Wilsonville, OR). The Tektronix OpenChoice TDSPCS1 software package was used for subsequent data processing and analysis.

The shear UPV $\left(\mathbf{U P V}_{\mathbf{S}}\right)$ values obtained with the respective transducers were calculated based on the time lapse from the signal's emission until its reception, called the time of flight (TOF). From the known distance $(d)$ velocity was determined: $\mathrm{UPV}=d / \mathrm{TOF}$. In addition, with the shear wave transducer values, the received signal has an initial longitudinal wave train, generated by mode conversion. These particular longi- 


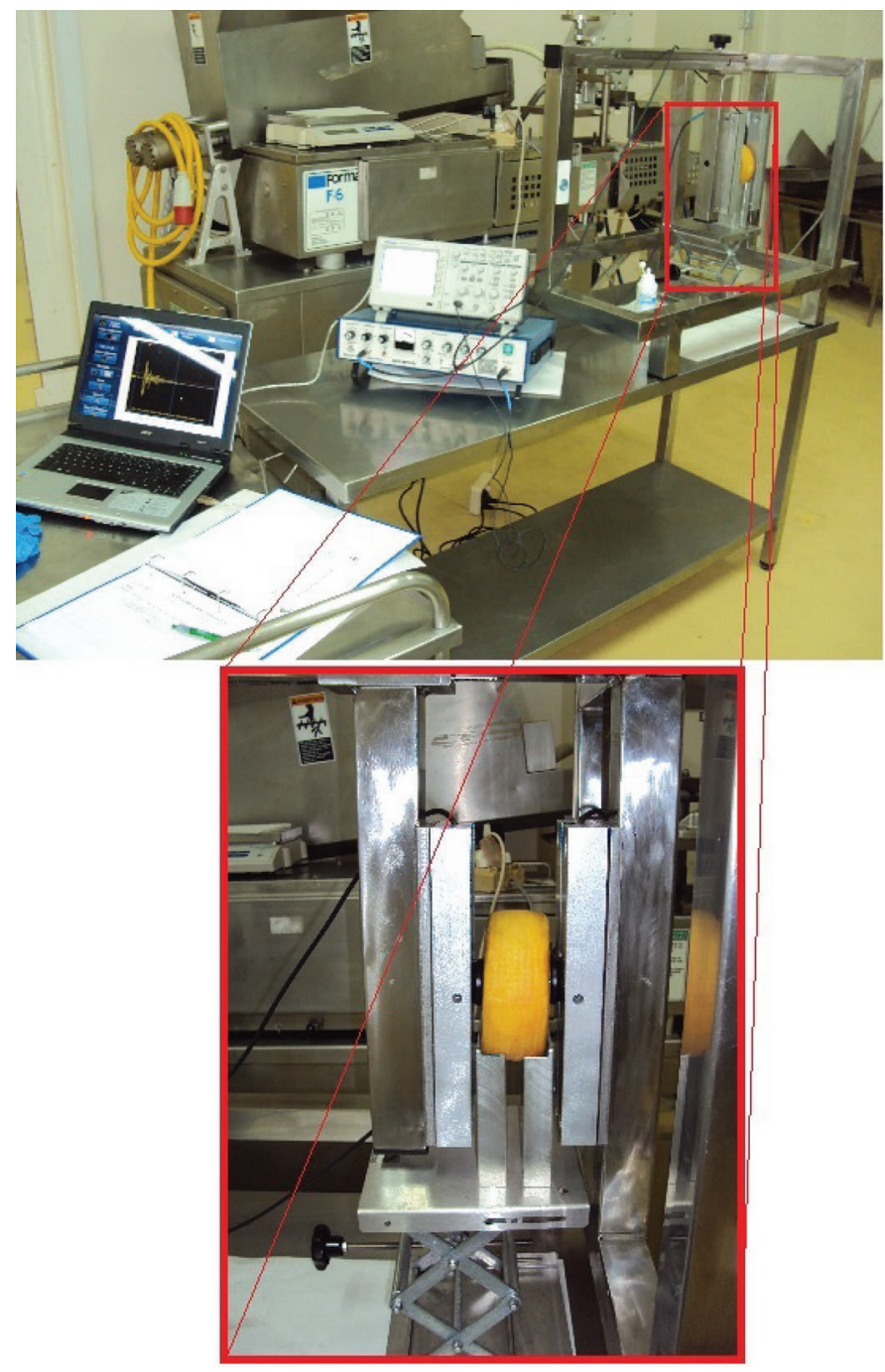

Figure 2. Custom-designed metal structure to ensure the perfect face-to-face alignment of the cheese.

tudinal waves $\left(\mathbf{U P V}_{\mathbf{L}}\right)$ were also obtained. Figure $1 \mathrm{~B}$ shows a typical A-scan obtained with one of the shear wave transducers. From $\mathrm{UPV}_{\mathrm{L}}, \mathrm{UPV}_{\mathrm{S}}$, and the apparent densities or specific weights $(\rho)$ of each sample, the following constants were calculated for each piece of cheese according to the expressions established by the
American Society for Testing and Materials (2008) in protocol ASTM D2845-08.

Young's modulus $(\boldsymbol{E})$ :

$$
E=\frac{\rho \times U P V_{S}^{2} \times\left(3 U P V_{L}^{2}-4 U P V_{S}^{2}\right)}{U P V_{L}^{2}-U P V_{S}^{2}} .
$$

Shear modulus $(\mu)$ :

$$
\mu=\rho \times U V P_{S}^{2} .
$$

Bulk modulus $(\boldsymbol{k})$ :

$$
k=\frac{\rho \times\left(3 U P V_{L}^{2}-4 U P V_{S}^{2}\right)}{3} .
$$

Lamé's constant $(\lambda)$ :

$$
\lambda=\rho \times\left(U P V_{L}^{2}-2 U P V_{S}^{2}\right) .
$$

Poisson's ratio $(\boldsymbol{\nu}):$

$$
\nu=\frac{\left(U P V_{L}^{2}-2 U P V_{S}^{2}\right)}{2 \times\left(U P V_{L}^{2}-U P V_{S}^{2}\right)} .
$$

Fast Fourier transform (FFT) frequencies corresponding to the 25th, 50th, 75th, and 99th percentiles (denoted respectively as $\mathrm{FFT}_{25}, \mathrm{FFT}_{50}, \mathrm{FFT}_{75}$, and $\mathrm{FFT}_{99}$ ) of the received signals in the cumulative frequency periodograms of the FFT, as well as the attenuation (denoted as AT 10, AT 20, AT 30, AT 40, AT 50, AT 60, AT 70, AT 80, and AT 90) quantified in terms of the time taken to receive the energy $(10,20,30,40,50$, $60,70,80$, and $90 \%$, respectively, of the total energy received), expressed as a multiple of the TOF, were also recovered (Cerrillo et al., 2014). These parameters were determined along the center of opposite faces of the

Table 1. Characteristics of the different transducer models used ${ }^{1}$

\begin{tabular}{lccccc}
\hline Model $^{2}$ & $\begin{array}{c}\text { Diameter } \\
(\mathrm{m})\end{array}$ & $\begin{array}{c}\text { Central } \\
\text { frequency }(\mathrm{kHz})\end{array}$ & $\begin{array}{c}-6 \mathrm{~dB} \\
\text { bandwidth }(\%)\end{array}$ & $\begin{array}{c}\text { Near-field } \\
\text { length }(\mathrm{cm})\end{array}$ & $\begin{array}{c}\text { Beam } \\
\text { angle }\left(^{\circ}\right)\end{array}$ \\
\hline V150 & 0.025 & 250 & 92 & 5.21 & 8.41 \\
V151 & 0.025 & 500 & 101 & 10.42 & 4.20 \\
\hline
\end{tabular}

${ }^{1}$ The value ultrasonic pulse velocity $=750 \mathrm{~m} / \mathrm{s}$ was applied in the calculation of near-field length and beam angle.

${ }^{2}$ The pulser-receiver models 5058PR and 5077PR (Olympus Panametrics NDT, Waltham, MA) were used for emission and reception of the ultrasonic signals with transducers V150 and V151, respectively. 
specimens for each of the selected inspection frequencies.

\section{Statistical Analysis}

Data were statistically analyzed using SPSS 15.0 for Windows (SPSS Inc., Chicago, IL). Descriptive statistics of the ultrasonic parameters were determined, and the evolution of the physicochemical, microbial, and texture parameters of the cheese batches was studied using 1-way ANOVA and separated by Tukey's honest significant difference test $(P \leq 0.05)$. The efficiency of the selected ultrasonic parameters as control markers of physicochemical and texture parameters of the cheese specimens was evaluated by Pearson correlation coefficients. For classification of cheese batches during their ripening, linear discriminant analysis (LDA) was applied to the ultrasonic data. The discriminant variables for each ripening interval evaluated $(2-4,4-6,6-8$, and 8-10 wk) were identified by a step-wise algorithm based on the Wilks' lambda method. The results of the LDA classification model with best performance were graphically represented by projecting the cheese groups into the space of discriminant functions (DF).

\section{RESULTS AND DISCUSSION}

\section{Physicochemical and Texture Parameters}

Table 2 presents the physicochemical and texture parameters of the cheese batches during the ripening process. In general, DM, total protein, and total fat increased during the ripening process, with ranges of 45.1 to $59.6,11.7$ to 19.3 , and 23.0 to $33.6 \%$, respectively, without differences among the batches studied at the end of ripening. In the same way, the results for ash, $\mathrm{pH}$, and density did not show any relevant differences among the studied batches during the ripening process. These physicochemical results were similar to those obtained previously for Torta del Casar and other similar soft-bodied cheeses (Roa et al., 1999; Sanjuán et al., 2002; Ordiales et al., 2013a). In contrast, texture data were more variable between batches. The firmness of the standard batch (ST) increased until the end of ripening, whereas for batch PD1, this tendency was not evident. In batch MD, maximal firmness occurred at 6 wk after ripening and then declined continuously. For batch PD2, this parameter was particularly high throughout ripening. Delgado et al. (2010) found a reduction of cheese hardness during the ripening of Torta del Casar, which is characteristic of this type of cheese. In this study, cheeses were previously opened by cutting the whole upper rind to evaluate the texture of the cheese paste. Data on the other measured texture parameters revealed the highest values for unctuosity and stickiness for batch MD. The effect of microbial population on the rheology properties of this type of cheese has been described by Pereira et al. (2010). The relationship between textural and proteolytic parameters has been attributed to the degradation of the casein matrix, decreasing the hardness and consistency of Torta del Casar and increasing its adhesiveness during ripening (Delgado et al., 2010). Conversely, batch PD1 showed lowest values for unctuosity and stickiness.

\section{Evolution of Microbial Population During Cheese Ripening}

The mean counts of LAB during ripening were greater than $8 \log \mathrm{cfu} / \mathrm{g}$ for all batches without significant differences (Figure 3). Yeast counts were essentially constant until wk 6 of ripening, with most values ranging from $4 \log \mathrm{cfu} / \mathrm{g}(\mathrm{PD} 2)$ to $6 \log \mathrm{cfu} / \mathrm{g}$ (MD and PD1). At the end of ripening, 3 batches showed a noticeably decreased yeast count, with values close to $4 \log \mathrm{cfu} / \mathrm{g}$ for MD and $3 \log \mathrm{cfu} / \mathrm{g}$ for ST and PD2. A similar evolution was observed for the Enterobacteriaceae population, with counts stable around $8 \mathrm{cfu} / \mathrm{g}$ in all batches during the initial 4 wk of ripening and a progressive decrease in the second period. However, batches ST and PD2 exhibited a more pronounced decline in this microbial group relative to batch PD1. The counts of LAB, yeast, and Enterobacteriaceae found in this study are similar to those previously reported in this type of cheese (Pintado et al., 2010; Ordiales et al., 2013a). Lactic acid bacteria appear to be the predominant microbial group in Torta del Casar (Mas Mayoral et al., 1991), in which they eventually reach viable numbers of $8 \mathrm{log} \mathrm{cfu} / \mathrm{g}$ by the time of consumption (Ordiales et al., 2013a). In addition, the presence of high numbers of Enterobacteriaceae is not unusual in soft cheese made from raw milk (Alegría et al., 2009; Gonçalves et al., 2018). These high levels of microorganisms during ripening suggest a relevant contribution of their associated activity in the development of the sensory characteristics of Torta del Casar cheese, including its texture.

\section{Ultrasonic Parameters}

The evaluation of the properties of food, including different types of cheese, mainly occurs through the analysis of the ultrasonic velocity as the simplest and the most reliable measurement (Benedito et al., 1998; Gallo et al., 2018). Benedito et al. (2000) noticed an increase in ultrasonic velocity during ripening of the firm-textured Cheddar cheese, ranging from 1,657 to $1,677 \mathrm{~m} / \mathrm{s}$ at $12^{\circ} \mathrm{C}$ and from 1,684 to $1,693 \mathrm{~m} / \mathrm{s}$ at $5^{\circ} \mathrm{C}$ (transducers of $1 \mathrm{MHz}, 1.9$-cm crystal diameter; model 
Crespo et al.: ULTRASOUND FOR QUALITY CONTROL OF TORTA DEL CASAR

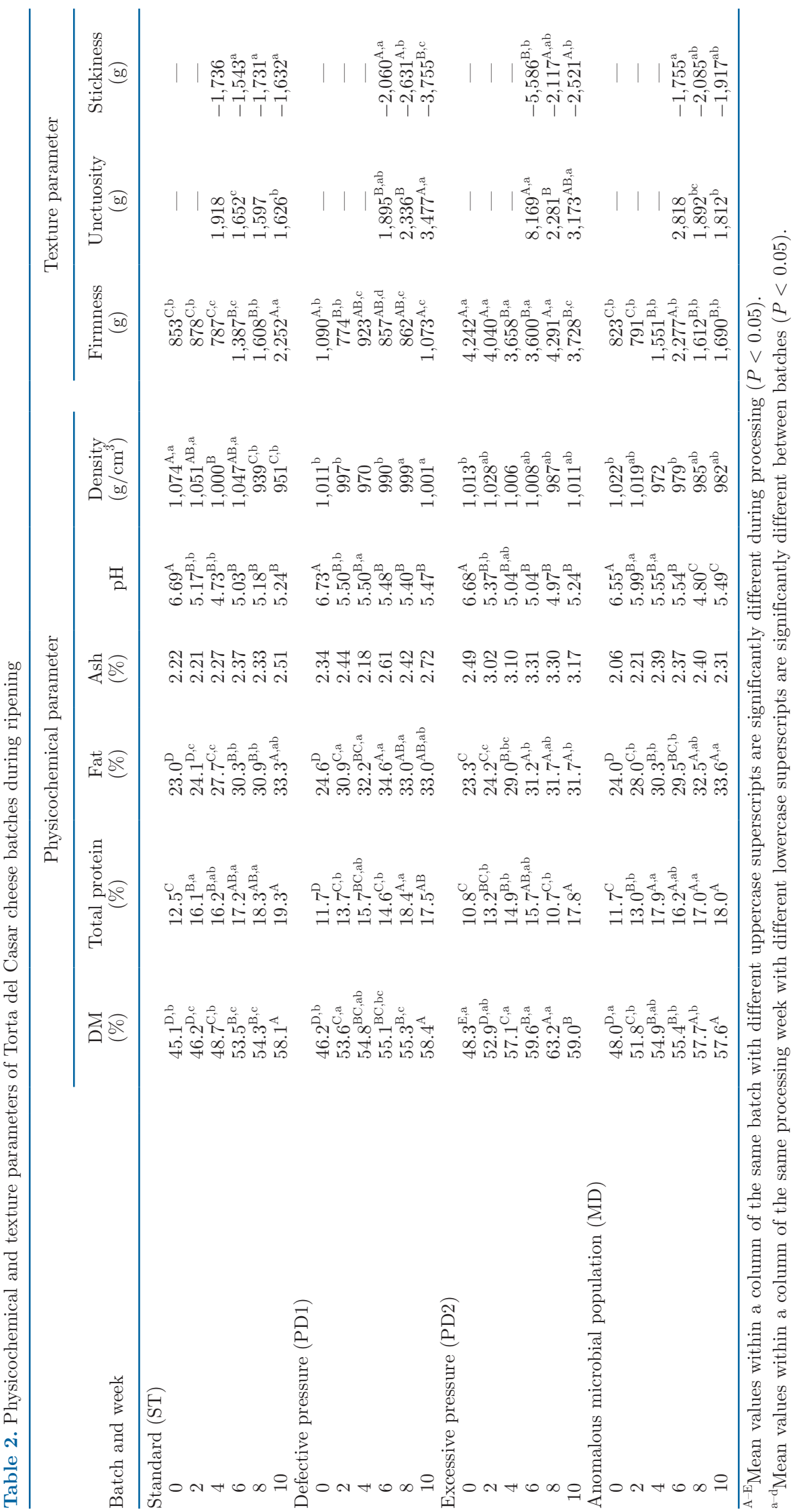



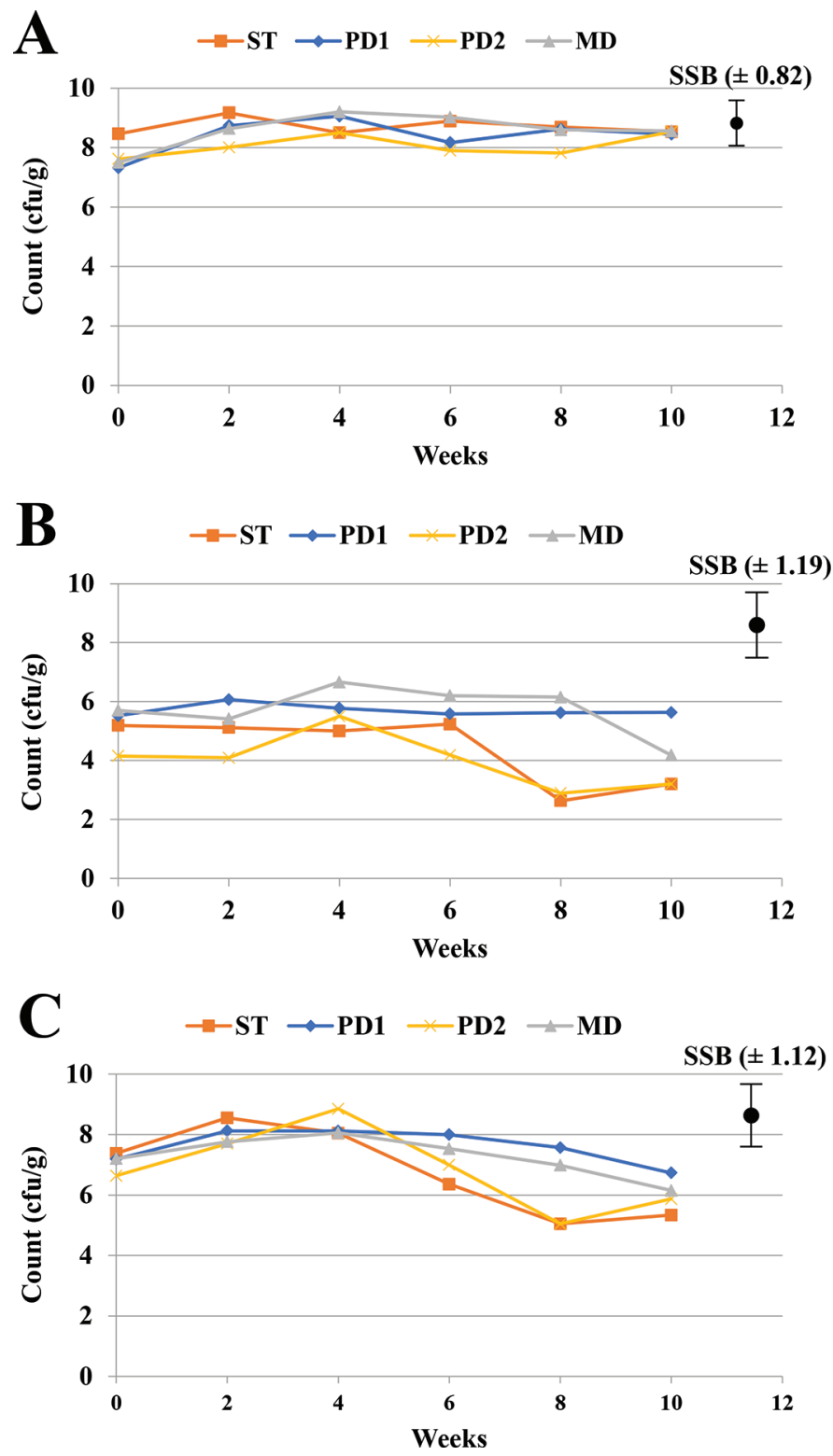

Figure 3. Evolution of (A) lactic acid bacteria, (B) yeast, and (C) Enterobacteriaceae counts during the ripening of the cheese batches studied: standard (ST), defective pressure (PD1), excessive pressure (PD2), and anomalous microbial population (MD). SSB = statistical significance bar using Tukey's honestly significant difference test.

A314S-SU, Panametrics NDT). These values are more constant than those found in this study for Torta del Casar, a soft-textured cheese, with ranges of 1,144 to 1,723 and 1,246 to $1,547 \mathrm{~m} / \mathrm{s}$ for transducers V150 and V151, respectively (Table 3 ).

Several parameters related to velocity, frequency, and attenuation were studied in this work. In addition to ultrasound velocity in the longitudinal (VL) and transverse (VT) directions and the velocity ratio (VT/ $\mathrm{VL}$ ), the elastic constants were calculated from the ultrasonic velocity measurements. From these parameters, VL showed the lowest relative standard deviation (3.71-5.18\%), whereas Lamé's constant and $v$ presented the highest coefficients of variation (40.37-48.47 and $30.37-38.08 \%$, respectively). In all cases, the level of dispersion of the parameters related to the velocity was higher with transducer V150 than with V151. On the contrary, the relative standard deviation values of the highest amplitude frequency and the FFT frequencies corresponding to the $25 \mathrm{th}, 50 \mathrm{th}, 75 \mathrm{th}$, and 99 th percentiles of the received signals were higher for transducer V151 than for V150, mainly for the highest amplitude frequency, showing more than $40 \%$ of the variability (Table 3). Regarding the attenuation-related parameters, the dispersion data were slightly higher with transducer V150 than with V151, with AT 60 showing the highest coefficients of variation for both transducers (35.6 and $31.2 \%$, respectively). The high variability found for some ultrasound parameters means that those could show a good response to the changes and variations in the physicochemical and texture parameters associated with the cheese defects or ripening process.

\section{Relationship Between Physicochemical and Texture Properties with Ultrasonic Parameters During Ripening of Soft Cheese Torta del Casar}

Correlations of the ultrasound parameters obtained using both transducers V150 and V151 with the physicochemical and texture properties of the Torta del Casar cheese batches during ripening are shown in Table 4. These results evidenced that transducer V150 performed better than transducer V151. Using transducer V150, the ultrasonic parameters presented a strong correlation $(P<0.01)$ with several physicochemical and texture parameters. The values of most velocity-related parameters and elastic constants were negatively correlated (positive in the case of $v$ ) with the fat in DM of the cheese samples during ripening, particularly for VT, E, and Shear modulus (Table 4). This inverse correlation between the fat content of food and ultrasound velocities (VL and VT) is a well-recognized phenomenon. Consequently, these parameters have been used to predict the fat percentage in meat products, fish, and different types of cheese (Park et al., 1994; Simal et al., 2003; Shannon et al., 2004; TelisRomero et al., 2011). Conversely, the fat content in DM of Torta del Casar was also the most important physicochemical parameter for explaining the attenuation behavior. The AT 70 value showed the highest correlation with fat in DM (Table 4). This indicates that when fat in DM increases, a given percentage of energy is received in a longer time (i.e., the attenuation decreases). Considering that the cheeses are less 


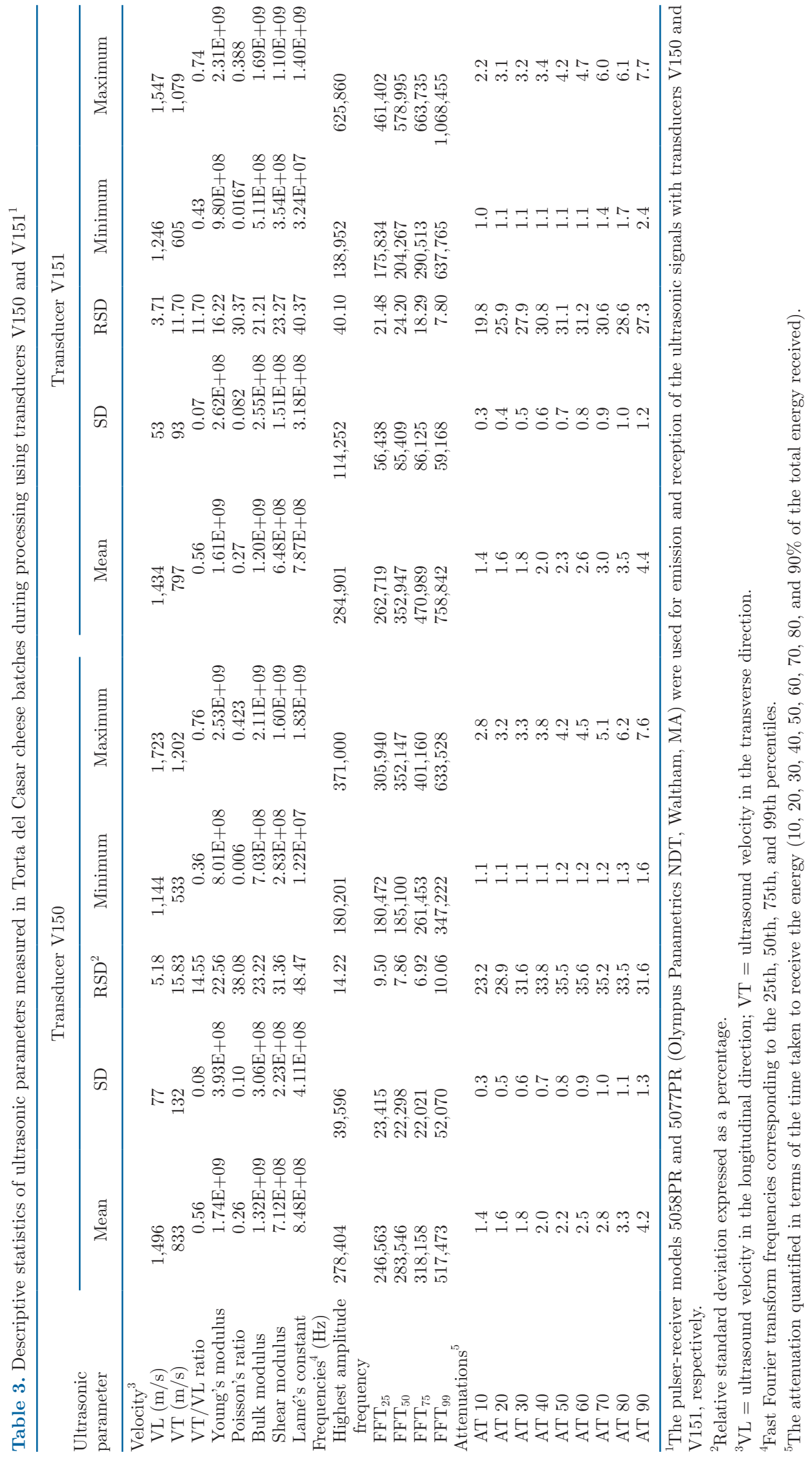


attenuating when the AT 70 value is greater, this result suggests that the most attenuating Torta del Casar cheese specimens are those with a lower ratio of fat in DM. In heterogeneous products, such as meat and fish, the attenuation coefficient is mainly associated with the scattering contribution (Buckin et al., 2002). In these cases, attenuation is much more sensitive to changes in the structure of the tissue than to changes in composition, which limits their use in composition analysis (Sigfusson et al., 2001; Awad et al., 2012). In semi-hard and hard cheeses, such as Manchego cheese, the number and size of holes of a particular cheese can mask the possible changes in attenuation during maturation (Benedito et al., 2001, 2006). However, attenuation has been proposed as a useful indicating parameter for detecting intramuscular fat (marbling) in homogeneous meat pieces, such as longissimus muscle (Park et al., 1994). In our study, Torta del Casar is a soft-type cheese with a relatively homogeneous paste, so both the dispersion and absorption by casein micelles and fat globules can be considered to provide a noticeable contribution to the attenuation. The attenuation coefficient due to scattering plays the same role as an intrinsic absorption coefficient in cheeses with a weak gas cavity concentration (Nassar et al., 2010).

A strong negative correlation between the density and both total fat and fat in DM of the studied cheeses was confirmed $(P<0.01)$. It can explain, at least partly, the lower values of the ultrasonic attenuation for denser cheese samples, whereas $k$ and Lamé's constant showed a positive correlation with the density of the cheeses (Table 4). However, as mentioned above, good correlations have already been found between penetrated acoustic signals and the density of porous food products (Awad et al., 2012), such as Torta del Casar.

Regarding the ash content, which mainly constitutes chloride and calcium salts, it was correlated with VL and $E$ (Table 4). These results corroborate those recorded by Dukhin et al. (2005), who described the ultrasound parameters related to the speed of sound as the better parameters for investigating effects on a molecular scale, whereas attenuation was considered more suitable for characterizing effects related to the heterogeneity and phase composition of the particular dairy product system, containing casein micelles and fat globules.

Among the texture properties of cheese, firmness was significantly related to the VL, as well as the attenuation coefficient, which showed a high negative correlation at AT 90 (Table 4). Again, this result would indicate a greater firmness of Torta del Casar cheese samples with more ultrasound attenuation and, consequently, with higher propagation speeds. Benedito et al. (2000) described the firmness as the textural pa- rameter best related to the ultrasonic velocity during the ripening of cheeses. In general, cheese maturation increases firmness, thereby increasing the ultrasonic velocity, whereas the attenuation coefficient can show a relatively high variability due to porosities or holes in the cheese samples (Benedito et al., 2002). However, in other food gels with bland taste and porous texture, such as tofu, the ultrasonic attenuation has been used as an alternative to textural or rheological analysis in gel characterization (Ting et al., 2009). In contrast, the results obtained for unctuosity seem to indicate that only ultrasonic parameters related to velocity and frequency would be reliable to determine this textural property of Torta del Casar. The unctuosity values showed a strong positive correlation with the values of VT, $E$, and Shear modulus but negative correlation with $v$ and $\mathrm{FFT}_{99}$.

These results suggest the efficacy of these ultrasonic parameters as tools for the development of discriminative models during Torta del Casar ripening based on their relationship with some physicochemical parameters (mainly fat in DM and density) and texture properties (firmness and unctuosity) of the cheese during ripening.

\section{Discrimination of Soft Cheese Defects by Ultrasound Parameters During Ripening}

The LDA was developed using ultrasonic parameters determined during the ripening of the different batches studied. Leave-more-out cross-validation with 4 cancellation groups was used for testing the predictive capability of the LDA. The results of the LDA for classification of different defects in Torta del Casar cheese as a function of the ripening duration are summarized in Table 5, which displays the ultrasonic variables selected by the stepwise algorithm per ripening phase, ordered according to decreasing importance and the number (and percentage) of correct classifications in both calibration and prediction. The LDA of the ultrasound data collected during the cheese ripening confirms the role of some parameters related to attenuation and velocity as useful tools for the discrimination of the types of cheese studied, besides revealing the discrimination potential of the $\mathrm{FFT}_{75}$. Regarding the attenuation parameters, AT 90 and AT 10 are among the discriminant variables of cheese at 2 to $4 \mathrm{wk}$ of ripening. In contrast, for the 4 to 6 - and 6 to 8 -wk intervals of ripening, AT 50 appears to be the most discriminant variable, although $\mathrm{FFT}_{75}$ was also an influential variable (Table 5). For the velocity-related parameters, $\mathrm{VL}, \mathrm{VT}, k, v$, and $E$ were also discriminants with a comparatively high weight in the LDA model of the last ripening period (8-10 wk). 


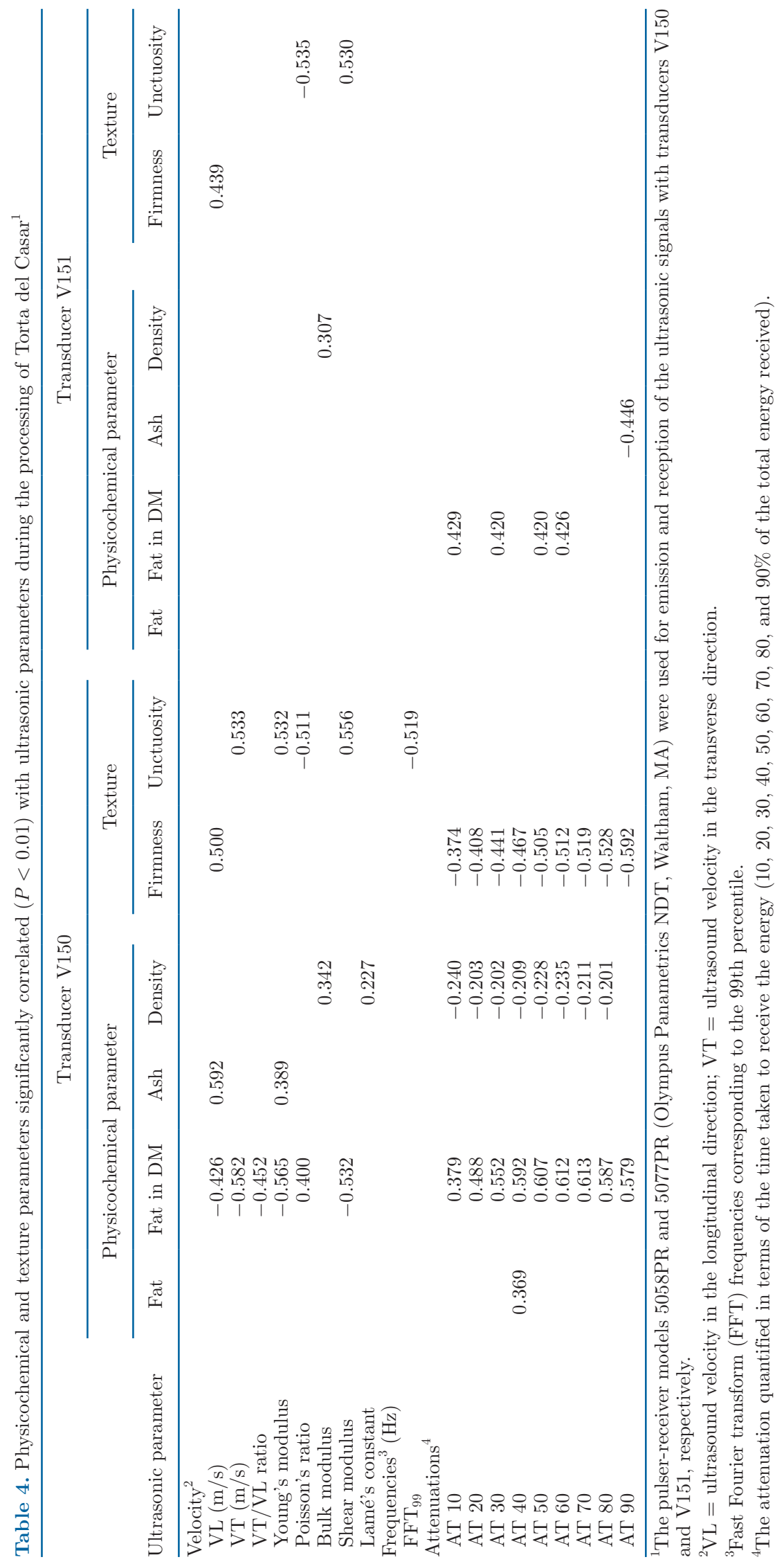


Table 5. Linear discriminant analysis classification applied to the Torta del Casar cheese samples during processing

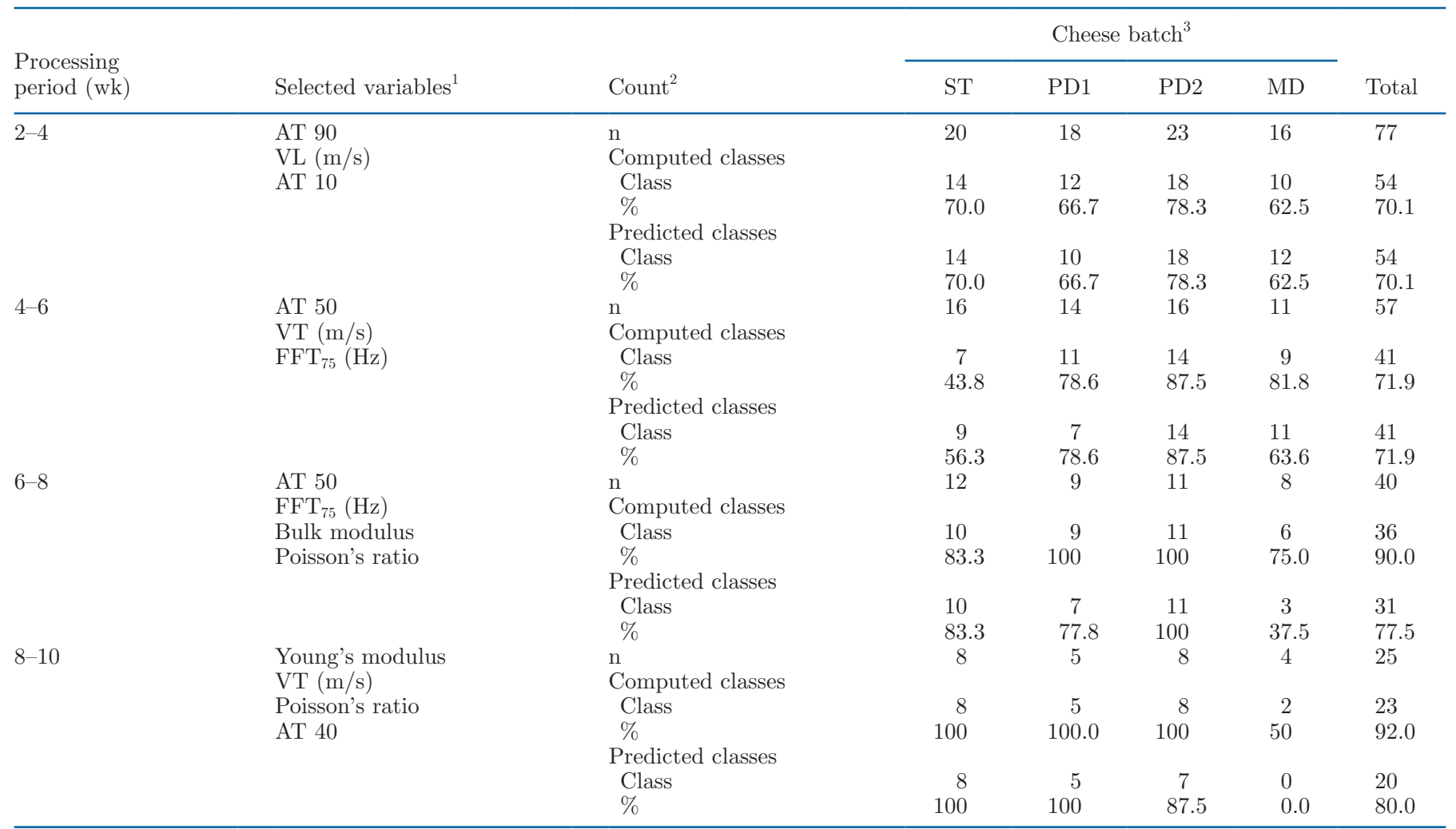

${ }^{1} \mathrm{VL}=$ ultrasound velocity in the longitudinal direction; $\mathrm{VT}=$ ultrasound velocity in the transverse direction. $\mathrm{FFT}_{75}=\mathrm{Fast}_{\mathrm{Fourier}}$ transform frequencies corresponding to the 75 th percentile. AT $=$ The attenuation quantified in terms of the time taken to receive the energy (40, 50 , and $90 \%$ of the total energy received).

${ }^{2}$ Class $=$ number of cases correctly classified; $\%=$ percentage of cases correctly classified.

${ }^{3} \mathrm{ST}=$ standard batch; PD1 = defective pressure batch; PD2 = excessive pressure batch; MD = microbial defect batch.

Table 6. Linear discriminant analysis classification applied to the Torta del Casar cheese samples after 6 to 8 and 8 to 10 wk of processing, considering the batches PD1 and MD one sample group

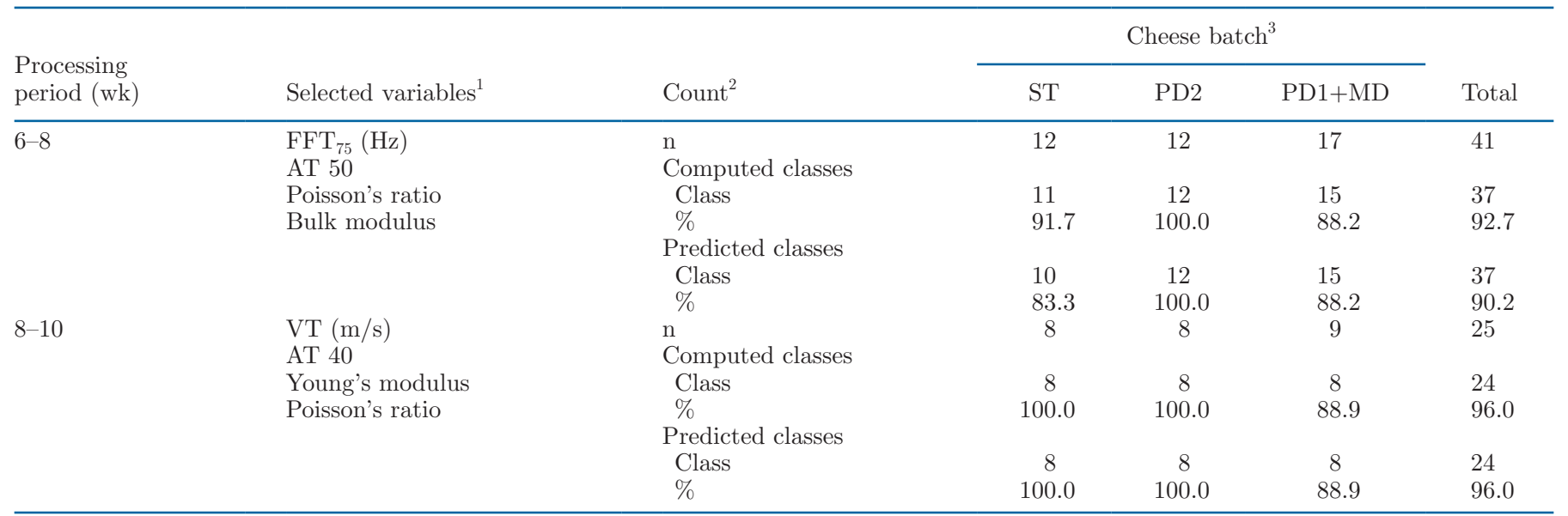

${ }^{1} \mathrm{VT}=$ ultrasound velocity in the transverse direction. $\mathrm{FFT}_{75}=$ Fast Fourier transform frequencies corresponding to the 75 th percentile. AT $=$ The attenuation quantified in terms of the time taken to receive the energy (40,50, and $90 \%$ of the total energy received).

${ }^{2}$ Class $=$ number of cases correctly classified; $\%=$ percentage of cases correctly classified.

${ }^{3} \mathrm{ST}=$ standard batch; PD1 = defective pressure batch; PD2 = excessive pressure batch; MD = microbial defect batch. 
The descriptive and predictive performance of the LDA models reflects the reciprocal location of cheese samples in the canonical space of the different ripening periods. In particular, the percentages of the total recognized external samples increased from 70.1 to $80.0 \%$ throughout the ripening periods analyzed (from $2-4$ wk to $8-10$ wk). In general, the correct predictions were relatively lower, between 0 and $65 \%$, for the PD1 cheese samples, mainly due to the misclassification of cheese samples from other batches (PD1 and MD) in the last periods of ripening (6-8 and 8-10 wk; Supplemental Tables S1 and S2, https://doi.org/10.3168/jds .2020-18160). There is high similarity between defects PD1 and MD in soft cheese from the textural viewpoint when the product is at the final stage of ripening. Accordingly, when the LDA models included both defects in the same group (PD1+MD), the percentages of the total external samples recognized were higher than $90 \%$ for 6 to 8 and 8 to $10 \mathrm{wk}$ of ripening (Table 6 ). Figure 4 displays the 40 and 25 cheese samples ripened during 6 to 8 and 8 to $10 \mathrm{wk}$, respectively, projected in the plane of the 2 DF. The LDA model based on the ultrasonic data of samples with 6 to 8 wk of ripening allowed for differentiation of the 3 groups. Different values of AT 50 and $\mathrm{FFT}_{75}$ had a relevant role in the differentiation of PD1+MD and PD2 samples, whereas $k$ and $v$ were the best discriminant parameters for differentiation of ST samples. In samples at 8 to 10 wk, all 3 cheese groups were located in distinct regions of the DF plane. In particular, ST cheese samples were well separated along DF1, whereas DF2 separated PD1+MD samples from PD2 samples by different values of $v$, AT 40, E, and VT.

\section{CONCLUSIONS}

In this paper, we discuss the usefulness of the ultrasound parameters to the quality control of the soft cheese Torta del Casar during ripening, confirming the high correlation between several ultrasonic parameters and both the physicochemical and textural properties of the final cheese product. To the best of our knowledge, in soft cheese, such as Torta del Casar, this is the first literature study to report the discrimination of defective cheeses during ripening by analyzing the ultrasonic parameters and, in turn, validating the on-line capability of ultrasound for nondestructive evaluation of the soft cheese-making process. During the intervals of 6 to 8 and 8 to $10 \mathrm{wk}$ of ripening, cheese samples included in PD1 and MD batches differed from the control in the attenuation values (mainly for AT 40 and AT 50). On the contrary, discrimination of cheeses with the PD2 defect (excessive pressure) was mainly based

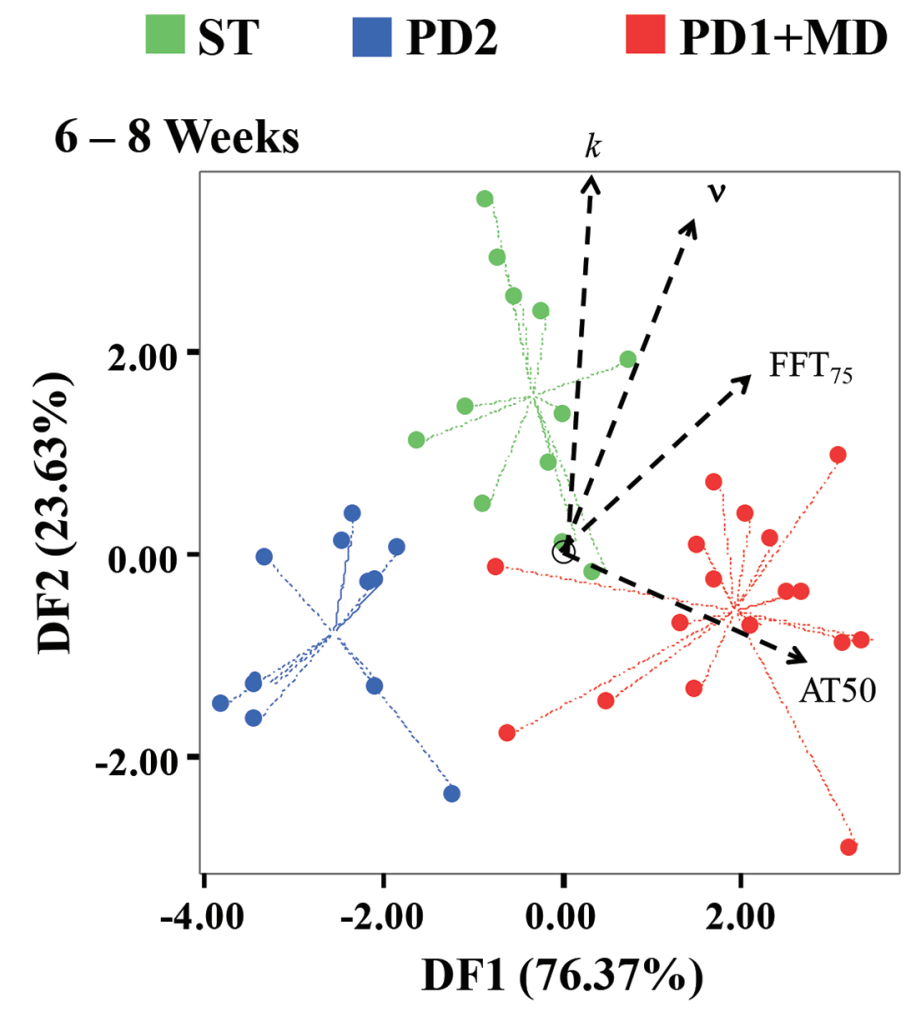

\section{8 - 10 Weeks}

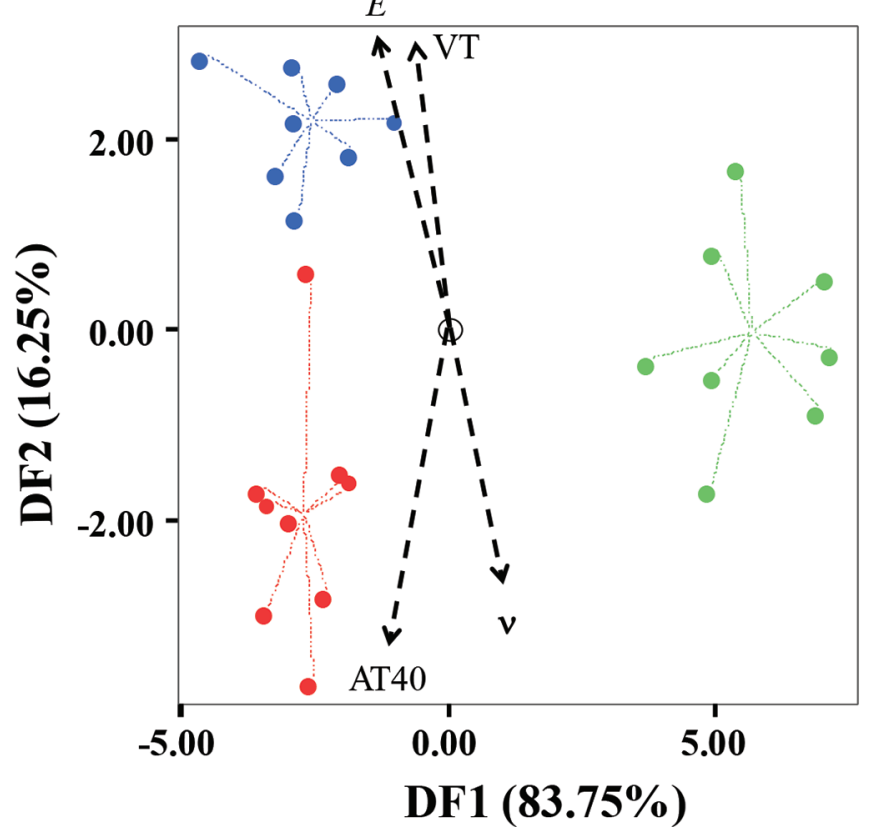

Figure 4. Cheese samples grouped into batches ( $\mathrm{ST}=$ standard; $\mathrm{DP} 1=$ defective pressure; $\mathrm{DP} 2=$ excessive pressure $\mathrm{MD}=$ anomalous microbial population) and variable loadings projected on discriminant function (DF) 1 and 2 planes for samples at 6 to 8 and 8 to $10 \mathrm{wk}$ of ripening. $k=$ bulk modulus; $v=$ Poisson's ratio; $E=$ Young's modulus; $\mathrm{FFT}_{75}=$ fast Fourier transform frequencies corresponding to the $75 \mathrm{th}$ percentile; $\mathrm{AT}=$ attenuation quantified in terms of the time taken to receive the energy; $\mathrm{VT}=$ ultrasound velocity in the transverse direction. 
on different values of some velocity-related ultrasound parameters, such as $v, k, E$, and VT.

\section{ACKNOWLEDGMENTS}

This work was supported by the Ministry of Science, Innovation and Universities of the Spanish Government [grant number CIT-060000-2008-0008]; research group support was from the Junta Extremadura Government (GR18165) and the European Regional Development Fund (ERDF). The authors are grateful to Hnos. Pajuelo SAT Dairy (Almoharin, Cáceres, Spain) and Diego Lindo (Hnos. Pajuelo SAT) for technical assistance and to PDO Torta del Casar (Casar de Cáceres, Cáceres, Spain) for technical support. The authors have not stated any conflicts of interest.

\section{REFERENCES}

Alegría, Á., P. Álvarez-Martín, N. Sacristán, E. Fernández, S. Delgado, and B. Mayo. 2009. Diversity and evolution of the microbial populations during manufacture and ripening of Casín, a traditional Spanish, starter-free cheese made from cow's milk. Int. J. Food Microbiol. 136:44-51. https://doi.org/10.1016/j.ijfoodmicro 2009.09.023.

AOAC International. 2000. Official Methods of Analysis. 15th ed. Association of Official Analytical Chemists, Arlington, VA.

American Society for Testing and Materials. 2008. ASTM D2845-08. Standard test method for laboratory determination of pulse velocities and ultrasonic elastic constants of rock (Withdrawn 2017). American Society for Testing and Materials, West Conshohocken, PA.

Awad, T. S., H. A. Moharram, O. E. Shaltout, D. Asker, and M. M. Youssef. 2012. Applications of ultrasound in analysis, processing and quality control of food: A review. Food Res. Int. 48:410-427. https://doi.org/10.1016/j.foodres.2012.05.004.

Benedito, J., J. Carcel, M. Gisbert, and A. Mulet. 2001. Quality control of cheese maturation and defects using ultrasonics. J. Food Sci. 66:100-104. https://doi.org/10.1111/j.1365-2621.2001.tb15589.x.

Benedito, J., J. A. Carcel, R. Gonzalez, and A. Mulet. 2002. Application of low intensity ultrasonics to cheese manufacturing processes. Ultrasonics 40:19-23. https://doi.org/10.1016/s0041 $-624 \mathrm{x}(02) 00085-9$

Benedito, J., J. A. Carcel, N. Sanjuan, and A. Mulet. 2000. Use of ultrasound to assess Cheddar cheese characteristics. Ultrasonics 38:727-730. https://doi.org/10.1016/S0041-624x(99)00157-2.

Benedito, J., N. Sanjuan, J. A. Carcel, and A. Mulet. 1998. Ultrasonic determination of cheese maturity. Pages 44-61 in Automatic Control of Food and Biological Processes: Proceedings of the Internal Symposium ACoFoP IV, Göteborg, Sweden.

Benedito, J., S. Simal, G. Clemente, and A. Mulet. 2006. Manchego cheese texture evaluation by ultrasonics and surface probes. Int. Dairy J. 16:431-438. https://doi.org/10.1016/j.idairyj.2005.04 .005 .

Buckin, V., E. Kudryashov, and B. O'Driscoll. 2002. High-resolution ultrasonic spectroscopy for material analysis. Am. Lab. 34:28-31.

Cerrillo, C., A. Jiménez, M. Rufo, J. Paniagua, and F. T. Pachón. 2014. New contributions to granite characterization by ultrasonic testing. Ultrasonics 54:156-167. https://doi.org/10.1016/j.ultras .2013.06.006

Cho, B. K., and J. M. K. Irudayaraj. 2003. A noncontact ultrasound approach for mechanical property determination of cheeses. J. Food Sci. 68:2243-2247. https://doi.org/10.1111/j.1365-2621.2003 .tb05754.x.
Cho, B. K., J. M. K. Irudayaraj, and S. Omata. 2001. Acoustic sensor fusion approach for rapid measurement of modulus and hardness of Cheddar cheese. Appl. Eng. Agric. 17:827-832. https://doi.org/ $10.13031 / 2013.6827$.

Delgado, F. J., J. Rodríguez-Pinilla, J. González-Crespo, R. Ramírez, and I. Roa. 2010. Proteolysis and texture changes of a Spanish soft cheese ('Torta del Casar') manufactured with raw ewe milk and vegetable rennet during ripening. Int. J. Food Sci. Technol. 45:512-519. https://doi.org/10.1111/j.1365-2621.2009.02157.x.

Dukhin, A. S., P. J. Goetz, and B. Travers. 2005. Use of ultrasound for characterizing dairy products. J. Dairy Sci. 88:1320-1334. https:/ /doi.org/10.3168/jds.S0022-0302(05)72798-3.

European Commission. 2003. Commission Regulation (EC) No 1491/2003 of 25 August 2003 supplementing the Annex to Regulation (EC) No 2400/96 (Ficodindia dell'Etna, Monte Etna, Colline di Romagna, Pretuziano delle Colline Teramane, Torta del Casar, Manzana de Girona or Poma de Girona). Off. J. Eur. Union, L 214/6 August 2003.

Gallo, M., L. Ferrara, and D. Naviglio. 2018. Application of ultrasound in food science and technology: A perspective. Foods 7:164. https: //doi.org/10.3390/foods7100164.

Gonçalves, M. T. P., M. J. Benito, M. de Guía Córdoba, C. Egas, A. V. Merchán, A. I. Galván, and S. Ruiz Moyano. 2018. Bacterial communities in Serpa cheese by culture dependent techniques, $16 \mathrm{~s}$ rRNA gene sequencing and high-throughput sequencing analysis. J. Food Sci. 83:1333-1341. https://doi.org/10.1111/1750-3841 .14141 .

Hæggström, E., and M. Luukkala. 2001. Ultrasound detection and identification of foreign bodies in food products. Food Control 12:37-45. https://doi.org/10.1016/S0956-7135(00)00007-4.

ISO (International Organization for Standardization). 2004. Cheese and processed cheese-Determination of the total solids content (Reference method). Standard number 5534:2004. ISO, Geneva, Switzerland.

ISO (International Organization for Standardization). 2008. CheeseDetermination of fat content-Van Gulik method. Standard number 3433:2008. ISO, Geneva, Switzerland.

ISO (International Organization for Standardization). 2014. Milk and milk products - Determination of nitrogen content-Part 1: Kjeldahl principle and crude protein calculation. Standard number 8968-1:2014. ISO, Geneva, Switzerland.

Jiménez, A., M. Rufo, J. M. Paniagua, A. T. Crespo, M. P. Guerrero, and M. J. Riballo. 2017. Contributions to ultrasound monitoring of the process of milk curdling. Ultrasonics 76:192-199. https://doi .org/10.1016/j.ultras.2017.01.007.

Koc, A. B., and B. Ozer. 2008. Nondestructive monitoring of renetted whole milk during cheese manufacturing. Food Res. Int. 41:745750. https://doi.org/10.1016/j.foodres.2008.05.008.

Lee, H. O., H. Luan, and D. G. Daut. 1992. Use of an ultrasonic technique to evaluate the rheological properties of cheese and dough. J. Food Eng. 16:127-150. https://doi.org/10.1016/0260 -8774(92)90024-Z.

Leemans, V., and M. F. Destain. 2009. Ultrasonic internal defect detection in cheese. J. Food Eng. 90:333-340. https://doi.org/10 .1016/j.jfoodeng.2008.06.042.

Mas Mayoral, M., J. González Crespo, and M. J. Nieto Villaseca. 1991. Casar cheese: Production, physicochemical and microbiological characteristics. Arch. Zootec. 40:359-369.

Nassar, G., F. Lefbvre, A. Skaf, J. Carlier, B. Nongaillard, and Y. Noêl. 2010. Ultrasonic and acoustic investigation of cheese matrix at the beginning and the end of ripening period. J. Food Eng. 96:1-13. https://doi.org/10.1016/j.jfoodeng.2009.06.029.

Ordiales, E., M. J. Benito, A. Martín, R. Casquete, M. J. Serradilla, and M. G. Córdoba. 2013a. Bacterial communities of the traditional raw ewe's milk cheese "Torta del Casar" made without the addition of a starter. Food Control 33:448-454. https://doi.org/10 .1016/j.foodcont.2013.03.027.

Ordiales, E., A. Martín, M. J. Benito, M. Fernández, R. Casquete, and M. G. Córdoba. 2014. Influence of the technological properties of vegetable rennet (Cynara cardunculus) on the physicochemical, 
sensory and rheological characteristics of 'Torta del Casar' cheese. Int. J. Dairy Technol. 67:402-409. https://doi.org/10.1111/1471 -0307.12129 .

Ordiales, E., A. Martín, M. J. Benito, A. Hernández, S. Ruíz-Moyano, and M. G. Córdoba. 2012. Technological characterisation by free zone capillary electrophoresis (FZCE) of the vegetable rennet $(C y$ nara cardunculus) used in "Torta del Casar" cheese-making. Food Chem. 133:227-235. https://doi.org/10.1016/j.foodchem.2012.01 .012 .

Ordiales, E., A. Martín, M. J. Benito, A. Hernández, S. Ruiz-Moyano, and M. G. Córdoba. 2013b. Role of the microbial population on the flavor of the soft-bodied cheese Torta del Casar. J. Dairy Sci. 96:5477-5486. https://doi.org/10.3168/jds.2013-6587.

Park, B., A. D. Whittaker, R. K. Miller, and D. S. Hale. 1994. Predicting intramuscular fat in beef longissimus muscle from speed of sound. J. Anim. Sci. 72:109-116. https://doi.org/10.2527/1994 $.721109 \mathrm{x}$

Pereira, C. I., J. A. Graça, N. S. Ogando, A. M. P. Gomes, and F. Xavier Malcata. 2010. Influence of bacterial dynamics upon the final characteristics of model Portuguese traditional cheeses. Food Microbiol. 27:339-346. https://doi.org/10.1016/j.fm.2009.10.012.

Pintado, A. I., T. G. Tavares, F. K. Tavaria, and F. X. Malcata. 2010 Tradition versus modernism in cheesemaking technology: A Portuguese case study encompassing plant coagulant, non-bovine milks and adventitious microflora. Aust. J. Dairy Technol. 65:128-134.

Roa, I., M. Belén López, and F. J. Mendiola. 1999. Residual clotting activity and ripening properties of vegetable rennet from Cynara cardunculus in La Serena cheese. Food Res. Int. 32:413-419. https: //doi.org/10.1016/S0963-9969(99)00098-8.

Sanjuán, E., R. Millán, P. Saavedra, M. A. Carmona, R. Gómez, and J. Fernández-Salguero. 2002. Influence of animal and vegetable rennet on the physicochemical characteristics of Los Pedroches cheese during ripening. Food Chem. 78:281-289. https://doi.org/ 10.1016/S0308-8146(02)00098-5.
Shannon, R. A., P. J. Probert-Smith, J. Lines, and F. Mayia. 2004. Ultrasound velocity measurement to determine lipid content in salmon muscle; the effects of myosepta. Food Res. Int. 37:611-620. https://doi.org/10.1016/j.foodres.2004.01.012.

Sigfusson, H., E. A. Decker, and D. J. McClements. 2001. Ultrasonic characterization of Atlantic mackerel (Scomber scombrus). Food Res. Int. 34:15-23. https://doi.org/10.1016/S0963-9969(00)00123 $-\mathrm{X}$.

Simal, S., J. Benedito, G. Clemente, A. Femenia, and C. Rosselló 2003. Ultrasonic determination of the composition of a meat-based product. J. Food Eng. 58:253-257. https://doi.org/10.1016/S0260 $-8774(02) 00375-8$

Telis-Romero, J., H. A. Váquiro, J. Bon, and J. Benedito. 2011. Ultrasonic assessment of fresh cheese composition. J. Food Eng. 103:137-146. https://doi.org/10.1016/j.jfoodeng.2010.10.008.

Ting, C. H., F. J. Kuo, C. C. Lien, and C. T. Sheng. 2009. Use of ultrasound for characterising the gelation process in heat induced $\mathrm{CaSO}_{4} \cdot 2 \mathrm{H}_{2} \mathrm{O}$ tofu curd. J. Food Eng. 93:101-107. https://doi .org/10.1016/j.jfoodeng.2009.01.015.

Tunick, M. H. 2000. Rheology of dairy foods that gel, stretch, and fracture. J. Dairy Sci. 83:1892-1898. https://doi.org/10.3168/jds .S0022-0302(00)75062-4.

\section{ORCIDS}

Abel Crespo 느 https://orcid.org/0000-0003-1605-7610

Alberto Martín (i) https://orcid.org/0000-0001-6104-8102

Santiago Ruiz-Moyano () https://orcid.org/0000-0003-0309-5888

María José Benito ำ https://orcid.org/0000-0001-8432-8035

Montaña Rufo @ https://orcid.org/0000-0002-3760-8795

Jesús M. Paniagua @ https://orcid.org/0000-0001-9756-9161

Antonio Jiménez @ https://orcid.org/0000-0002-2750-4132 